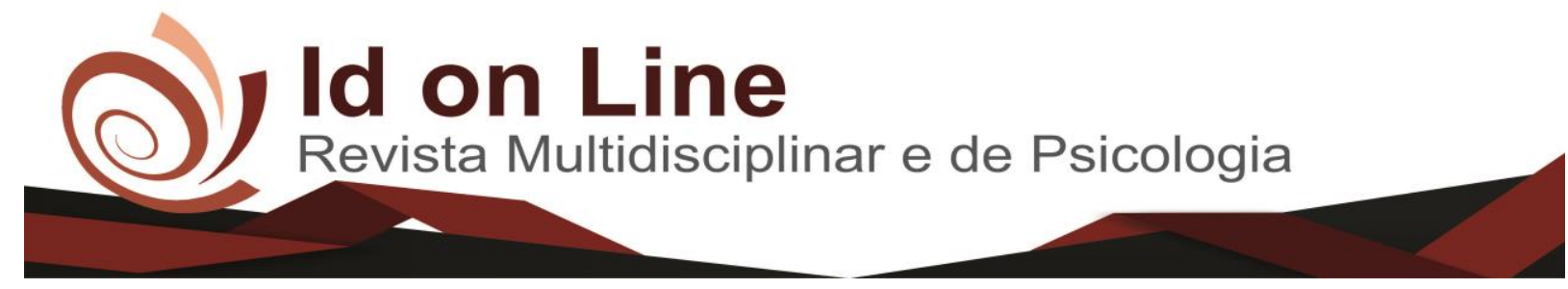

Artigo de Revisão

\title{
Evolução Histórica do Cooperativismo no Setor Agropecuário
}

\author{
Fernanda Ribeiro Teixeira ${ }^{l}$; Márcia Regina Aguiar ${ }^{2}$; Tiago da Silva ${ }^{3}$; \\ Mariana Emídio Oliveira Ribeiro ${ }^{4}$;Bianca Inez Antoniolli ${ }^{5}$
}

\begin{abstract}
Resumo: Ao considerar a importância e a influência do sistema cooperativista na economia do Brasil, o estudo traz uma análise qualitativa determinante. Este artigo tem como objetivo geral demonstrar as características do cooperativismo e retratar sua importância à sociedade e à economia brasileira, e ressaltar sua importância aos cooperados. A fim de atingir o objetivo proposto, utilizou-se como método a pesquisa bibliográfica que se consistiu nas pesquisas em livros, revistas, periódicos e materiais artigos referentes ao assunto proposto. No presente artigo conhece-se a realidade do cooperativismo agropecuário, além disso, este sistema é considerado como alicerce democrático, pois possibilita que os cooperados estabeleçam uma relação entre si, de colaboração e bem estar social. Entretanto, o cooperativismo permite às unidades familiares o desenvolvimento tanto para o consumo quanto o comercio de seus produtos estimulando o crescimento social e a preservação ambiental e evitar o êxodo rural, as cooperativas agropecuárias são instituições de influência direta sobre as propriedades familiares, porém, qualificadas como extensão da propriedade do cooperado, suas ações vão além dos fatores econômicos e produtivos. No entanto, possibilita aos cooperados a aperfeiçoamento produtivo e tecnológico no desenvolvimento de suas atividades, às cooperativas tem a possibilidade de influenciar o homem do campo a permanecia na zona rural.
\end{abstract}

Palavras-Chave: Cooperativismo Influencia e Bem estar Social

\section{Historical Evolution of Cooperativism in Agricultural Sector}

\begin{abstract}
Considering the importance and influence of the cooperative system in Brazil's economy, the study brings a decisive qualitative analysis. This article aims to demonstrate the characteristics of cooperativism and portray its importance to society and the Brazilian economy, and to emphasize its importance to the cooperative. In order to reach the proposed objective, a bibliographical research was used as a method that consisted of researches in books, journals, periodicals and material articles referring to the proposed subject. In this article the reality of agricultural cooperatives is known, and this system is considered as a democratic foundation, since it allows cooperatives to establish a relationship among themselves, of collaboration and social well-being. However, cooperativism allows households to develop both for consumption and trade in their products, stimulating social growth and environmental preservation and avoiding rural exodus, agricultural cooperatives are institutions that have a direct influence on family farms, but qualified as an extension of the cooperative's property, its actions go beyond economic and productive factors. However, it allows cooperatives to improve their production and technology in the development of their activities, cooperatives have the possibility of influencing rural man to remain in the countryside.
\end{abstract}

Keywords: Cooperative, Influence and Social Welfare

\footnotetext{
${ }^{1}$ Acadêmica do $8^{\circ}$ semestre do curso de Administração da Faculdade de Alta Floresta FAF.

2 Acadêmica do $8^{\circ}$ semestre do curso de Administração da Faculdade de Alta Floresta FAF.

${ }^{3}$ Acadêmico do $8^{\circ}$ semestre do curso de Administração da Faculdade de Alta Floresta FAF.

${ }^{4}$ Professora do curso de Administração da FAF. Professora do curso de Ciências Contábeis da FAF. Professora de ensino técnico e profissionalizante do SECITEC de Alta Floresta-MT. Mestranda do Programa de Pós Graduação em Ambiente e Desenvolvimento PPGAD da Universidade do Vale do Taquari UNIVATES. Especialista em Didática do Ensino Superior. Especialista em Gestão Estratégica de Pessoas. Especialista em Planejamento, Implantação e Gestão do EAD. Graduada em Administração.

${ }^{5}$ Professora do curso de Administração da FAF. Professora do curso de Ciências Contábeis da FAF. Especialista em Didática do Ensino Superior. MBA em Gestão Estratégica de Negócios. MBA em Gestão Estratégica de Pessoas.

128 Id on Line Rev. Mult. Psic. V.11, N. 39. 2017 - ISSN 1981-1179

Edição eletrônica em http://idonline.emnuvens.com.br/id
} 


\section{Introdução}

Diante de um cenário de grandes mudanças econômicas, nasce o cooperativismo, que é uma forma sólida de produzir em grupo. O sistema cooperativo é considerado o alicerce democrático de uma instituição, e tem como objetivo a geração de emprego, a distribuição de renda, a defesa do meio ambiente e a segurança alimentar. Além disso, o cooperativismo no Brasil surgiu por volta do século XIX, sendo que, a primeira cooperativa surgiu, em limeira em São Paulo, no ano de 1891. Sendo que, foi nas décadas de 50 e 60 que expandiu no país. cooperativismo é um instrumento de modificação socioeconômico do ser humano é algo essencial para a obtenção da felicidade do cooperado e sua família, por meio dessa sociedade o ser humano passa ganhar mais espaço em razão da existência. Além disso, por motivos tradicionais a região sul possui traços culturais de seus antepassados europeus que possuíam uma visão formal do cooperativismo com vários ramos de atuação, porém, em outras regiões as cooperativas se desenvolviam de uma forma lenta, o que dificultava o crescimento dos associados.

No entanto, para o projeto do cooperativismo se concretizar existem normas internas a serem seguidas como, respeitar o código de ética que é presidida pela instituição, a qual a pessoa é membro. Se por um lado, o cooperativismo possibilita que o associado tenha onde entregar seus produtos, por outro lado as regras internas impossibilitam que o cooperado entregue os produtos produzidos á terceiros. Sendo que, objetivo da associação é proporcionar aos usuários condições financeiras de todos os membros.

Além disso, cabe aos dirigentes da cooperativa promover ações educativas e de esclarecimentos sobre os benefícios que a instituição obterá ao comercializar seus produtos internamente, e os malefícios caso venha entregar para atravessadores. Nota-se que, os cooperados por possuir pouco grau de conhecimento sobre a necessidade da união mútua geram atrito, pois o mesmo vê a entidade com unicamente com obrigações de atender suas necessidades.

O cooperativismo destina-se por intermédio de uma sociedade de pessoas organizadas que buscam satisfazer suas necessidades de bens e serviços e programas educativos e sociais. Entretanto, cooperativa, é uma empresa constituída de pessoas para pessoas, e regulamentada 
pela lei nº5. 764/71, sendo que, mediante a regulamentação estabelecida é reconhecida no Brasil, e no mundo como uma cooperativa que produz bens e serviços.

Segundo Thenório Filho (1999) as raízes do cooperativismo existem desde a época do império dos faraós, os trabalhadores já se organizavam para executarem seus projetos em grupo. Outras civilizações como os Incas e os Astecas também partilhavam desse sistema de cooperação. Visto que, a organização Inca trabalhava em comum, e a produção agrícola e pastoril era dividida, o trabalho era prestado de acordo com a necessidade de cada participante.

$\mathrm{Na}$ civilização Asteca, o rei repartia as terras para que as pessoas pudessem produzir, porém as terras continuavam sendo de propriedade do rei. Entretanto, essas duas civilizações possuíam as seguintes semelhanças; Eram homens livres que produziam nas terras do rei, e não eram assalariados.

Utilizavam sistema de irrigação coletiva combatiam pragas, construíam obras de proteção envoltas das terras que lhes pertenciam e emprestavam sementes entre si no caso de alguém fizesse uma má colheita. Sendo que, essas duas civilizações deixaram um legado para as gerações futuras, de como é o sistema de cooperativismo e a importância para a sobrevivência do homem.

Segundo Benato, (1994) outro relato formal do cooperativismo surgiu no século XVIII, na Inglaterra idealizada por Dr.William King e Owen, que influenciaram o meio operário a organizarem cooperativas, neste período surgi em 1820, a liga para a propaganda da cooperação. Em 1823, já existiam em torno de 300 cooperativas, porém com curta duração, pois os cooperados vendiam seus produtos a preço de custo.

Do mesmo modo, Benato relata que, em 1835 surgi na França na cidade de Lyon, a associação Lionesa,que desapareceu por repreensões policiais. No entanto, a primeira cooperativa formal foi idealizada pelos tecelões de Rochdale que trabalhavam entre 17 a 18 horas por dia, moravam em casas com condições precárias, e alimentação lhes custava muito cara, por isso, consumia toda sua renda.

Com o avanço das novas tecnologias, como a introdução de máquinas a vapor nas fábricas, muitos operários perderam o seu posto de trabalho, consequentemente não tinham o que comer, vestir, e um local para morar. Portanto deste modo, surge a necessidade de protegerem contra o desemprego e se manterem vivos através de uma cooperativa, até encontrar um emprego para subsidiar suas necessidades. 
O autor relata que, os cooperados cultivavam uma área rural, necessário para sua sobrevivência, gerando empregos a serem preenchido pelos companheiros excluídos do mercado de trabalho. Entretanto, a situação estava insustentável, em novembro de 1843, se uniram para discutir sobre planos para o futuro, e surgiram três opções para solucionar os problemas.

Entre elas, a proposta era emigrar para outras cidades a fim de buscar novas possibilidades, abster-se de bebidas alcoólicas, por que acreditavam que eram um grande sacrifício, e fundar um armazém cooperativo onde pudessem ajudar uns aos outros. Porém, a última opção de formação de um armazém foi aprovada por todos. E Todos os associados tinham como objetivos conseguir um capital de uma libra para subsidiar a ideia.

Em 28 de outubro de 1844, em Rochdale, distrito de Lancas Hire, na Inglaterra, a cooperativa foi formada por 27 homens e 1 mulher que foi nomeada como cooperativa de Rochdale Equitable Pioneers/Society Limited. No entanto, com o capital dos sócios, compraram uma grande quantidade de mercadorias com preço reduzido e aplicava o percentual de mercado, o que possibilitará um ganho extra, com o sucesso da cooperativa de Rochdale outras associações começaram a aparecer.

Considerando a importância e a influência do sistema cooperativista na economia brasileira, e as modificações socioeconômicas do ser humano, o bem estar familiar dos associados e a democracia no âmbito institucional. Observou-se que, o cooperativismo é um grande aliado do produtor rural, pois, permite que os cooperados superem suas dificuldades com maior facilidade.

Portanto, o sistema de cooperativismo traz facilidade ao associado ao adquirir insumos, venda dos produtos, distribuição de renda e a qualidade de vida do ser humano. Diante disso, o principal problema dessa pesquisa é como o cooperativismo influencia o setor agropecuário?

Nesse sentido, o presente trabalho teve como objetivo esclarecer a sociedade à realidade do cooperativismo agropecuário. Sendo que, os objetivos específicos é descrever a evolução do cooperativismo e suas influencias no setor agropecuário, e comparar as inovações da administração, para o setor de cooperativismo agropecuário.

Conclui-se que cooperativismo é uma junção de forças entre pessoas que buscam atingir os mesmos objetivos. Sendo que, os cooperados visam o equilíbrio harmonia, a distribuição da renda, igualdade mútua e uma sociedade mais justa para todos. 


\section{Metodologia}

A metodologia foi realizada para verificar as fases históricas do cooperativismo através de pesquisas bibliográficas no setor agropecuário, para ressaltar as características do cooperativismo e retratar sua importância à sociedade e à economia brasileira, $\mathrm{O}$ método utilizado para a pesquisa será o método indutivo.

Segundo Lakatos (2010, p.166) "a pesquisa bibliográfica, ou de fontes secundarias, abrange toda bibliografia já tornada publica em relação ao tema de estudo, desde publicações avulsas, boletins, jornais, livros, pesquisas, monografias, teses, material cartográfico etc., ate meios de comunicação oral: radio gravações em fita magnética e audiovisuais". A pesquisa bibliográfica que se consistiu nas pesquisas em livros, revistas, periódicos e materiais artigos referentes ao assunto proposto.

Lakatos comenta que, o método indutivo ocorre à generalização, pelo qual passa de um caso particular para um caso universal.

\footnotetext{
Indução é um processo mental por intermédio do qual, partindo de dados particulares, suficientemente constatados, infere-se uma verdade geral ou universal, não contida nas partes examinadas. Portanto, o objetivo dos argumentos indutivos é levar a conclusões cujo conteúdo é muito mais amplo do que o das premissas nas quais se basearam (LAKATOS, 2007, p. 68).
}

No entanto, a pesquisa exploratória qualitativa abrange formulação de questões ou de um problema com intuito de estudar os fatos como: "desenvolver hipóteses, aumentar a familiaridade do pesquisador com o ambiente, fato ou fenômeno, para realização de uma pesquisa futura mais precisa ou modificar e classificar conceitos" (LAKATOS, 2007, p. 171).

\section{Embasamento Teórico}

O sistema cooperativo é composto por três fases, como: cooperação, cooperativa, e cooperativismos, segundo o autor Nogueira ET AL (2005, p.12) "Cooperação vem do verbo latim cooparari, de cum e operari, que tem como significado produzir em conjunto".

Segundo Benato, (1994) em 1843, na Alemanha na cidade de Delitzch, surgiu a cooperativa de credito, onde os cooperados visaram à ajuda entre si, sendo que, recusaram 
auxílios do estado. Entretanto, a ideia de cooperativa de crédito se expandiu e passou a ser adotado por várias cidades para atender as necessidades dos agricultores.

Por volta de 1864, o conceito, de cooperativa chega na Itália, tendo como precursor Luigi Luzzatti, descendente de família israelita, criou a cooperativa voltada para linha de crédito, o chamado banco popular. O lema era "Ajuda-te, Deus e o estado de ajudarão". No entanto, no século XX o cooperativismo se concretiza e fortalece. Surgiram em torno de 810 mil cooperativas no mundo, e possuía 140 milhões de adeptos.

Evidentemente, com a expansão, do cooperativismo em 1891 na cidade de limeira são Paulo foi criado a associação cooperativa dos empregados da companhia telefônica.

Em 1895 e 1897 na cidade de campinas de são Paula a cooperativa dos empregados da companhia paulista de estrada de ferro. Porém, com a vinda dos imigrantes alemães, italianos e japoneses fugitivos da segunda guerra foi nesse período que a cooperativa foi consolidada. Além disso, a importância da evolução do cooperativismo agropecuário no Brasil proporciona o direcionamento do ramo agropecuário presente na região, demonstrando os grupos de cooperativas que se desenvolvem e contribuem para economia.

No entanto, conhecer as inovações das cooperativas, situar as modalidades que podem ser o caminho para um futuro empreendedor consistente a realidade local, e verificar a história do trabalho do cooperativismo no ramo agropecuário tendo como fonte de conhecimento autores que facilite o melhor entendimento sobre o assunto estudado.

Entretanto, as cooperativas agropecuárias se compõem de produtores rurais, agropastoris e pesca. Tendo como base, a solidariedade em grupo, o bem estar coletivo, sendo que, tema estudado traz inúmeros benefícios como: a modificação econômica do ser humano, fixar os agricultores e pecuaristas no campo e fomentar a produtividade com a comercialização de seus produtos, desenvolvendo serviços para seus cooperados.

Consequentemente, há uma defasagem dentro do setor agropecuário. $\mathrm{O}$ setor agropecuário não se encontra em defasagem, pelo que consta o cooperativismo agropecuário participa ativamente na economia brasileira, é o que consolida a Organização das Cooperativas do Brasil (OCB, 2015).

A organização das cooperativas do Brasil demonstra que,

Esse segmento é responsável pelo aumento do produto interno bruto (PIB) do país em cada setor tem metas de desenvolvimento e existem gargalos, em que os produtores rurais enfrentam, os chamado fora da porteira, está o déficit no armazenamento de grãos. Porém, o país produz cerca de 160 milhões de toneladas 
de grãos, enquanto os armazéns comportam menos de 140 milhões de toneladas. Essa defasagem causa prejuízos à atividade agrícola, pois compromete a comercialização e o abastecimento interno (OCB, 2015).

De acordo com Alves (2003), no início do século XX, surgi o cooperativismo agropecuário no Brasil, e passa por diversas transformação, como momentos de estagnação e fortalecimento, contudo seu desenvolvimento acontece na forma de ciclos. O último se inicia no ano 2000, quando o crescimento foi maior.

$\mathrm{Na}$ metade do século XX, pode se encontrar duas fases de desenvolvimento das cooperativas. Entre as décadas de 1960 e 1970, que se caracterizou pela estruturação, auxiliado por políticas que deram modernidade para a agricultura, uma delas é a política de subsidio financeiros. De acordo com autores, Alves (2003), Gonçalves (1994), e Vegro (1994), este período representou o auge para as cooperativas, este momento em que, os valores chegaram ao máximo de 140 bilhões de reais em 1979. O montante era de $\mathrm{R} \$ 875$ bilhões (Anuário Estatístico do Crédito Rural, BCB).

A primeira fase é o de crescimento do setor, e esta aponta para a tendência das cooperativas agropecuárias se tornarem grandes empresas, ligadas não somente a comercialização de produtos, mas passando por processo de agro industrialização e diversificação de atividades (DELGADO, 1985).

Com isto, ocorreria certo controle do mercado por essas instituições, Contudo, há inversão neste panorama nas décadas de 1980 e 1990, com o período de recessão, relacionada à crise econômica e política do país. Entretanto, a partir da segunda metade da década de 1980 se inicia a segunda fase dos ciclos médios da economia brasileira, que coincide com a fase do ciclo da economia mundial, o que faz desse momento um período de forte crise para o Brasil. Nessa condição, os valores do crédito rural oficial passam a cair drasticamente (DELGADO, 1985).

Portanto entre, as décadas de 1980 e 1990 ocorreu redução das políticas voltadas à agropecuária. Não somente o crédito rural entrou em crise, outras políticas desenvolvidas até então foram reduzidas ou extintas, como a Política de Garantia de Preços Mínimos (PGPM), os programas de Aquisição do Governo Federal (AGF) e Empréstimos do Governo Federal (EGF). Todo esse contexto contribui para instaurar a crise para cooperativas agropecuárias. Com as dificuldades para obtenção de recursos, e o distanciamento das políticas de incentivos, 
há uma reorganização no setor cooperativo, pautada na busca por novas fontes de crédito (DELGADO, 1985).

Com o fim do crédito, os cooperados desenvolveram outras meios para obter capital, onde diferentes mecanismos financeiros vieram atender as demandas existentes. Isso acarretou em uma série de ações por parte das cooperativas agropecuárias, como buscar recursos financeiro, tanto para si, como aos cooperados. Encontram então, o financiamento via títulos privados, certificados de mercadorias negociados em bolsas de mercadorias, e a troca de produtos por insumos (BELIK; PAULILLO, 2001).

Assim, de acordo com Gimenes et al. (2008), as cooperativas agropecuárias teriam que atuar como bancos, fornecendo recursos para os produtores rurais que não conseguiam captálos no mercado financeiro. No entanto, recursos de terceiros, traz para o cooperativismo riscos crescentes, coloca em perigo a integridade financeira, caso houver inadimplência dos produtores.

$\mathrm{Na}$ década de 1990 com a estagnação da economia, e as mudanças, como o rebaixamento dos preços agrícolas, e a sob valorização da moeda, houve o crescente índice de endividamento das cooperativas. De um lado, as dívidas agrícolas foram pagas, mas por outro, os preços agrícolas ficaram congelados (DA CUNHA FILHO; PINHEIRO, 2008).

Com isso, houve melhora na evolução das políticas de financiamento agrícola para as cooperativas, no entanto, neste período houve o crescimento deste setor. Segundo Filho e ainda em 2003, através da Instrução Normativa $n^{\circ} 358$, editada pelo Governo Federal, foi eliminada a cobrança do PIS/COFINS para as cooperativas agropecuárias e de infraestrutura (PINHEIRO, 2008).

No início do governo Lula em 2003, muda o panorama político, e a aproximação de 1998, se intensifica com a administração. Entretanto, prosseguindo com a política de incentivos às cooperativas, neste mesmo ano posto o Programa de Desenvolvimento Cooperativo para Agregação de Valor à Produção Agropecuária (PRODECOOP).

Visto que, esse programa tinha o objetivo de implementar e dar competitividade no complexo agroindustrial das cooperativas brasileiras, usando a modernização dos sistemas produção e de comercialização, sendo desenvolvidas pacotes financeiros para a construção de silos e armazém, estruturas de recebimento de grãos, agro industrialização, entre outros, entram na pauta dessa nova política. Sendo que, em 2003 e 2011 foram aplicados via PRODECOOP cerca de R \$ 5,1 bilhões, em 3.072 operações (ALVES, 2003). 
Segundo Neves (2005), uma das ações que levam as cooperativas a ganharem posições no ranking das maiores empresas no Brasil, é ampliação do nível de maturidade e sustentabilidade, a qual aumenta a cada dia, ainda que em uma economia tão concorrida. Visto que, seus funcionários e cooperados, melhoram a sua capacidade gerencial e tecnológica e reduzem os impactos sobre o meio ambiente e social na qual estão inseridas, isso graças suas intensas capacitações. as cooperativas começam a ganhar autoridade e confiança para alcançar o sucesso no mercado competitivo, visando o fortalecimento de seu staff.

O autor ainda cita que, as cooperativas passa a ser o agente financeiro para seus cooperados, auxilia nas vendas e financiamentos de projetos para seus negócios. Com o auxílio da cooperativa, o cooperado passa a ter mais segurança.

Segundo OCB (1973), o cooperativismo tem sucesso no agronegócio e entre os produtores devido aos serviços prestados a estes, pode-se citar o barateamento da produção através de insumos com menores preços, além, da assistência técnica ofertada aos cooperados, assim como o apoio na venda dos seus produtos, o que tem gerado um aumento da remuneração dos produtores cooperados.

De acordo com, Cenzi (2009), o cooperativismo é a resposta para os eventuais problemas de muitos países e setores da economia, mas primordial países que necessitam do agronegócio, como o Brasil. Ao afirmar, o autor atesta que a "prova disso é que, nas comunidades onde existem cooperativas, o IDH - Índice de Desenvolvimento Humano é ligeiramente maior" (CENZI, 2009. p. 37).

De acordo com a publicação do DENACOOP (2006), o cooperativismo visa a qualidade de vida da sociedade, gera mais empregos, renda e arrecadando tributos. Entretanto desta forma, nota-se que o cooperativismo é um campo muito favorável para desenvolvimento em todo o mundo.

Portanto, sua influência é citada desta forma pelos autores Spanevello e Lago (2003) em estudo apontam que as cooperativas agropecuárias são instituições de influência direta sobre as propriedades familiares, porém qualificadas como extensão da propriedade do cooperado, suas atuações vão muito além dos aspectos econômicos e produtivos.

No entanto, oferece aos cooperados através de assistência técnica, o fornecimento de crédito, comercialização da produção, constitui o aperfeiçoamento produtivo e tecnológico, as cooperativas têm a possibilidades de melhorar a vida de muitos na sociedade. 


\section{Resultados e Discussões}

O cooperativismo vem para dinamizar, as inúmeras anomalias provocadas pela exploração de mão de obra, visto que, essa organização gera inclusão sendo uma forma de inclusão social de pequenos grupos e, os torna grande quando formam uma cooperativa. No entanto, cooperativa compete no mercado com as maiores concorrente e o estabelece vantagens competitivas por parte de cooperativas tem o apelo da economia social, que se for explorada pode tornar uma grande vantagem em relação às outras empresas.

Entretanto, os objetivos deste trabalho foram conhecer a realidade do cooperativismo agropecuário e descrever a evolução do cooperativismo e suas influencias no setor agropecuário, entretanto comparar as inovações da administração para este setor.

De acordo com a problemática do assunto Spanevello e Lago (2003) explicam em estudo que as cooperativas agropecuárias são como grandes empresas de influência sobre as famílias e suas propriedades, porem qualificadas como extensão da propriedade e seus cooperados, suas ações vão além dos aspectos econômicos e produtivos.

No entanto, oferece aos cooperados através de assistência técnica, o fornecimento de crédito, comercialização da produção, constituído ali o aperfeiçoamento produtivo e tecnológico, às cooperativas tem o suporte em dar permanência na propriedade.

Segundo Thenório Filho, (1999) as raízes do cooperativismo existem desde a época do império dos faraós, os trabalhadores já se organizavam para executarem seus projetos em grupo. Outras civilizações como os Incas e os Astecas também partilhavam desse sistema de cooperação. Visto que, a organização Inca trabalhava em comum, e a produção agrícola e pastoril era dividida o trabalho era prestado de acordo com a necessidade de cada participante.

O cooperativismo e as formas de cooperação é algo da história da humanidade. Se tem registros sobre a cooperação e a associação solidária desde a Pré-História da civilização, em tribos indígenas ou em antigas civilizações como os Babilônicos (BIALOSKORSKI NETO, 2006).

As cooperativas são capazes de agir em mercados, sem distinguir pequenos produtores e maiores e podendo ainda controlar melhor os preços da produção primária, certificar qualidade e produtos pelo relacionamento mais próximo que possuem com os produtores (MARASCHIN, 2004, p.35). 
Do mesmo modo, quando há junção de mão de obra os cooperados conseguem produzir tornando-os um grupo com auto potencial. Porém, o cooperativismo é somar capacidade dentro de um mundo de concorrência, sendo uma maneira de preservar a força econômica e vida dos indivíduos de um mesmo padrão e tipo, com objetivos comuns e com as mesmas necessidades. A cooperativa sempre surge em momentos de dificuldades e da consciência e fragilidade do homem dentro do mundo em que vive.

De acordo com Utumi (1974 apud NOGUEIRA et al., 2005, p. 13),

\begin{abstract}
As cooperativas representa a humanização das empresas econômicas e o "suplemento da alma" de que a sociedade moderna tanto carece, para repetir a oportuna expressão de Bergson. E ainda conceitua que a cooperativa tem sido entendida como "empresa de serviço" cujo fim é a prestação de serviços a seus usuários, que as criam com seu próprio esforço e risco. Distinguisse" empresa capitalista “, porque, nesta, a satisfação das necessidades dos usuários não representa seu fim imediato, mas sim um rendimento do seu bem investido.
\end{abstract}

Deste modo, o cooperativismo preza o bem estar social e humanizado dos cooperados a suprir as necessidades básicas das famílias, sendo que, o capitalismo visa apenas a obtenção de lucro e exploração do ser humano. Entretanto, é possível distinguir o cooperativismo do capitalismo através objetivos sociais e de suas necessidades.

\title{
Considerações Finais
}

O cooperativismo tem grande importância na economia, visto que, uma cooperativa oferece a ajuda necessária aos produtores, desde conhecimentos técnicos até a aquisição de maquinário para a produção rural, o que proporciona aos seus associados vários benefícios, além dos oferecidos pelo Governo. Visto que, o cooperativismo é um método de obtenção de lucro mutuamente. ele financia o desenvolvimento das cooperativas agropecuárias e melhora as atividades com dois tipos recursos: capitais próprios e capitais de terceiros.

O objetivo geral deste trabalho foi conhecer a realidade do cooperativismo agropecuário, mostrando-o como é importante a produção e cooperação quando o trabalho resulta em desenvolvimento mutuo.

Percebe-se nas pesquisas realizadas que, a evolução do cooperativismo e suas influências no setor agropecuário. Entretanto, é necessário que tenha equilíbrio entre esses 
fatores, que possa desenvolver suas atividades para não colocar sua autonomia financeira em risco. No entanto, mostra que, o cooperativismo é um importante instrumento para promover o desenvolvimento sustentável e a geração de renda.

No entanto, ao comparar as inovações da administração para este setor, fica claro a importância para cooperativa agropecuária quanto de outro seguimento, onde, flui o fortalecimento com seu processo de transformação. Uma cooperativa traz mudança e benefícios para os cooperados em todos os aspectos, com destaque, as áreas econômicas e sociais.

Dessa maneira, os associados são os próprios gestores da cooperativa, além disso, elimina a relação empregado - empregador, essa diferença faz que os interesses entre gerentes e cooperados, caminhem para um resultado sólido a todos, pois gerentes também são cooperados buscando entre sim as melhores condições que possibilite resultados acompanhado de desenvolvimento.

A cooperativa elimina o propósito do intermediário, pois o cooperado produz e vende por meio da cooperativa que lhe oferece preços acessíveis para sua valorização, isto lhe recorre a melhores preços, pois a qualidade do produto ofertado é maior.

$\mathrm{O}$ cooperativismo permiti que, às unidades familiares o desenvolva tanto para a comercialização de seus produtos em mercados extremamente competitivos. Espero que,este estudo contribuía para que haja uma ampla reflexão, não excluindo outros estudos e outras pesquisas na área. Entretanto, o cooperativismo está sempre no alcance de benefícios que muitas vezes tem o diferencial, no que proporciona a união das pessoas em cooperativas.

\section{Referências}

ALVES, André Gustavo de M. P. As cooperativas agropecuárias e o BRDE Histórico, Situação Atual e Perspectivas. Diretoria de Planejamento, BRDE. Novembro/2003.

BANCO CENTRAL DO BRASIL. Anuário Estatístico do Crédito Rural. Brasília: BACEN, vários anos. BANCO CENTRAL DO BRASIL. Manual do Crédito Rural.

BENATO, João Vitorino Azolim. OABC do cooperativismo Secretaria de agricultura e abastecimento de SP 1994. 
BELIK, Walter. PAULILLO, Luiz Fernando. Mudanças no Financiamento da Produção Agrícola Brasileira. São Paulo, 2001.

BIALOSKORSKI, Neto Sigismundo. Aspectos Econômicos das Cooperativas. Belo Horizonte: Mandamentos, 2006.

CENZI, Nerii Luiz. Cooperativismo; desde as origens ao projeto de lei de reforma do sistema Cooperativo brasileiro. / Nerii Luiz Cenzi. / $1^{\mathrm{a}}$ ed. (ano 2009), $2^{\mathrm{a}}$ reimpr. / Curitiba: Juruá, 2012. 172p.

DELGADO, Guilherme da C. Capital Financeiro e Agricultura no Brasil. São Paulo: Unicamp/Cone, 1985.

DENACOOP em ação / Ministério da Agricultura, Pecuária e Abastecimento. - Evolução do Cooperativismo no Brasil. Brasília, 2006. 124 p. Disponível em: $<$ https://www.google.com.br/url?sa=t\&rct=j\&q=\&esrc=s\&source=web\&cd=4\&cad=rja\&uact $=8 \& v e d=0$ ahUKEwiSxr6o5LzXAhWJQZAKHfcCALUQFgg2MAM\&url=http $\% 3 \mathrm{~A} \% 2 \mathrm{~F} \% 2 \mathrm{~F}$ www.dominiopublico.gov.br\%2Fpesquisa\%2FDetalheObraDownload.do\%3Fselect_action\%3 D\%26co_obra\%3D51509\%26co_midia\%3D2\&usg=AOvVaw22sTQnvd_lE8_PM9_cYK-u>. Acesso em: 27 Out. 2016.

DA CUNHA FILHO, Miguel H. da Cunha; PINHEIRO, José César V. Algumas considerações sobre o cooperativismo agrário brasileiro. Tex to publicado pela

SOBER, 2008. Disponível em: https://www.google.com.br/url? sa=t\&rct=j\&q=\&esrc=s\&source=web\&cd=1\&cad=rja\&uact= 8\&ved=0ahUKEwjy47G95LzXAhXHgpAKHWoqB0QQFggmMAA\&url=http\%3A\%2F\%2F www.repositorio.ufc.br\%2Fbitstream\%2Friufc\%2F5196\%2F1\%2F2004_eve_jcvpinheiroa.pd f\&usg=AOvVaw1RPaLI2vaD8dYxpDVShtYC.Acesso em: agosto de 2016.

GIMENES, Régio M. T.; et al. Evolução do crédito rural no Brasil e o papel das cooperativas agropecuárias no financiamento dos produtores rurais. XLVI SOBER, 2008, Rio Branco - Acre. Disponível em: https://www.google.com.br/url? sa $=t \& r c t=j \& q=\& e s r c=s \&$ source=web $\& c d=1 \& c a d=r j a \& u a c t=$ 8\&ved=0ahUKEwjjnvWX5LzXAhWDIpAKHXuqD18QFggmMAA\&url=https\%3A\%2F\%2 Fageconsearch.umn.edu\%2Frecord\%2F112618\%2Ffiles\%2F855.pdf\&usg=AOvVaw3aYPKO3uymPfdueuCq9kr. Acesso em: agosto de 2016.

GONÇALVES, José Sidnei; VEGRO, Celso Luís R. Crise econômica e cooperativismo agrícola: Uma discussão sobre os condicionantes das dificuldades financeiras da Cooperativa Agrícola de Cotia (CAC). Agricultura em São Paulo, SP, 41(2): 57-87, 1994.

MARCONI, Marina de Andrade e LAKATOS, Eva Maria. Fundamentos da Metodologia Científica. $7^{\circ}$ edição, editora: Atlas S.A São Paulo, 2010.

MARASCHIN, A. As relações entre os produtores de leite e as cooperativas: um estudo de caso na bacia leiteira de Santa Rosa - RS. 2004. 145 f. Dissertação (Mestrado) - 
Programa de Pós-Graduação em Desenvolvimento Rural. Universidade Federal do Rio Grande do Sul, Porto Alegre, 2004.

NEVES, Marcos Fava - Agronegócio do Brasil. ZYLBERSZTAJN Décio e Evaristo Marzabal Neves; prefácio de Roberto Rodrigues. São Paulo: Saraiva 2005.

NOGUEIRA, et al. Arnaldo Mazzi Nogueira, et al, gestão social, estratégias e parcerias, $4^{\circ}$ edição,2013 Editora Saraiva SP.

OCB. Organização das Cooperativas Brasileiras. Cooperativismo: evolução no Brasil. Disponível em: http://www.ocb.org.br/site/cooperativismo/evolucao_no_brasil.asp>.

Acesso em: 27 Out. 2016.

SPANEVELlO, Rosani Marisa; LAGO, Adriano, Jovens rurais do município de Nova Palma-RS: situação atual e perspectivas. Dissertação de Mestrado, Curso de Pós-Graduação em Extensão Rural/ Universidade Federal de Santa Maria, Santa Maria, 2003.

SANTOS, Helio. A busca de um caminho para o Brasil- a trilha do círculo vicioso. São Paulo Senac, 2001

SPANEVELLO, R. M.; LAGO, A. As cooperativas agropecuárias e a sucessão profissional na agricultura familiar. In: CONGRESSO DA SOCIEDADE

BRASILEIRA DE ECONOMIA E SOCIOLOGIA RURAL, 45. 2007, Londrina. Anais... Londrina: Sociedade Brasileira de Economia e Sociologia Rural, 2007.

CD ROM. WOORTMANN, E. F. Herdeiros, parentes e compadres.

THENÓRIO FILHO, Luiz Dias, Pelos Caminhos do Cooperativismos: Com destino ao Crédito mútuo; Luiz Dias Thenório Filho - São Paulo: Central das Cooperativas de Crédito do Estado de São Paulo, $1^{\circ}$ edição 1999.

Como citar este artigo (Formato ABNT):

TEIXEIRA, Fernanda R.; AGUIAR, Márcia Regina; SILVA, Tiago da; RIBEIRO, Mariana Emídio O.; ANTONIOLLI, Bianca I. Evolução Histórica do Cooperativismo no Setor Agropecuário. Id on Line Revista ultidisciplinar e de Psicologia, 2017, vol.12, n.39, p.128-141. ISSN: 1981-1179.

Evolução Histórica do Cooperativismo no Setor Agropecuário

Recebido: 15.11 .2017

Aceito: 18.11 .2017 